\title{
Efeito do tamanho das sementes de trigo no desenvolvimento inicial das plantas e no rendimento de grãos ${ }^{(1)}$
}

\author{
Christian Bredemeier ${ }^{(2)}$, Claudio Mario Mundstock ${ }^{(3)}$ e Daniel Büttenbender ${ }^{(4)}$
}

\begin{abstract}
Resumo - O objetivo deste trabalho foi avaliar o efeito do tamanho de sementes de trigo no desenvolvimento inicial das plantas e no rendimento de grãos. Os experimentos foram realizados em câmara de crescimento $\left(20^{\circ} \mathrm{C}\right.$ de dia e $10^{\circ} \mathrm{C}$ de noite; 12 horas de luz por dia) e no campo, com a densidade de 300 sementes $/ \mathrm{m}^{2}$. Os tratamentos constaram de diferentes tamanhos de semente, classificadas conforme o diâmetro (menor que $3,0 \mathrm{~mm}$ a maior que $3,75 \mathrm{~mm}$ ). Sob condições controladas, as plantas originadas de sementes maiores apresentaram maior taxa de emissão de folhas; as primeiras folhas do colmo principal apresentaram maior massa seca e maior comprimento. Estas plantas também foram superiores na freqüência de emissão do primeiro afilho, massa seca dos primeiros afilhos, e número de afilhos por planta. A superioridade inicial das plantas originadas de sementes grandes não propiciou um aumento do rendimento de grãos no experimento de campo.
\end{abstract}

Termos para indexação: Triticum aestivum, etapas de desenvolvimento, plântulas, brotação, componentes de rendimento.

\section{Effect of seed size on initial plant growth and grain yield of wheat}

\begin{abstract}
The objective of this work was to evaluate the effect of seed size on the initial plant growth and grain yield of wheat. The experiments were carried under chamber growth $\left(20^{\circ} \mathrm{C}\right.$ at day and $10^{\circ} \mathrm{C}$ at night; 12 hours light/day) and field conditions, with 300 seeds $/ \mathrm{m}^{2}$ density. Treatments consisted of seeds with different size, classified according to the diameter (less than $3.0 \mathrm{~mm}$ to higher than $3.75 \mathrm{~mm}$ ). Under controlled conditions, plants originated from larger seeds showed higher leaf emission rate, and their first three leaves had higher mass and length. These plants presented higher first tiller emission, higher tiller dry matter and more tillers/plants. The early advantages derived from larger seeds were not presented on final grain yield on the field.
\end{abstract}

Index terms: Triticum aestivum, developmental stages, seedlings, sprouting, yield components.

\section{Introdução}

As relações entre o tamanho da semente e o desenvolvimento das plantas de trigo têm sido relatadas em trabalhos como os de Peterson et al. (1989), Grieve \& Francois (1992) e Mian \& Nafziger (1994).

\footnotetext{
(1)Aceito para publicação em 27 de setembro 2000.

(2) Universidade Federal do Rio Grande do Sul (UFRGS), Faculdade de Agronomia, Dep. de Plantas de Lavoura, Caixa Postal 776, CEP 91540-970 Porto Alegre, RS E-mail: bredemei@voy.terra.br

(3)UFRGS, Faculdade de Agronomia, Dep. de Plantas de Lavoura, Bolsista do CNPq. E-mail: cmmundst@ufrgs.br

(4)UFRGS, Faculdade de Agronomia. E-mail: buttenbender@zipmail.com.br
}

Eles mostram que plântulas originadas de sementes grandes apresentaram maior estatura e acumularam mais massa seca, em comparação com plântulas originadas de sementes pequenas (Lafond \& Baker, 1986; Grieve \& Francois, 1992), além de emitirem maior quantidade de afilhos (Peterson et al., 1989; Mian \& Nafziger, 1994) e raízes (Peterson et al., 1989). A habilidade das sementes grandes em produzir plântulas maiores é mais pronunciada em condições de baixa disponibilidade hídrica (Mian \& Nafziger, 1994), alta salinidade (Grieve \& Francois, 1992), semeadura profunda (Mian \& Nafziger, 1994) ou baixo suprimento de $\mathrm{N}$ pelo solo, aumentando, assim, a importância das reservas da semente como fonte de nutrientes para o crescimento inicial da planta (Lowe \& Ries, 1973). O tamanho da semente, em 
muitas espécies, é indicativo de sua qualidade fisiológica (Popinigis, 1977).

O desenvolvimento da planta de trigo, quando medido pela taxa de emissão de folhas no colmo principal, pode ser afetado pela quantidade de reservas da semente, e seu efeito é mais pronunciado nos estádios iniciais do desenvolvimento (Peterson et al., 1989). Nesse período, quando as reservas da semente estão sendo utilizadas, a taxa de emissão de folhas em plântulas oriundas de sementes grandes é maior do que em plântulas oriundas de sementes pequenas (Peterson et al., 1989). A vantagem inicial na emissão de folhas pode manter-se durante todo o período em que novas folhas são emitidas (Peterson et al., 1989; Grieve \& Francois, 1992) e resultar em incrementos no rendimento de grãos (Grieve \& Francois, 1992). Outros autores, porém, verificaram que as vantagens do maior tamanho de semente foram limitadas aos estádios iniciais de desenvolvimento e não contribuíram para o aumento do rendimento de grãos (Mian \& Nafziger, 1994). Essas discrepâncias podem ser atribuídas a diferenças no ambiente em que os trabalhos foram realizados; a maioria é conduzida em condições controladas, normalmente em câmara de crescimento (Peterson et al., 1982) ou casa de vegetação (Grieve \& Francois, 1992).

Poucos trabalhos têm avaliado o efeito do maior tamanho da semente sobre o rendimento de grãos, em trigo, no campo. Quando isto ocorre, geralmente é causado pelo aumento nos componentes do rendimento, que são determinados durante os estádios iniciais de desenvolvimento (Grieve \& Francois, 1992), especialmente o número de espigas por planta. Este componente está diretamente relacionado à emissão e sobrevivência dos afilhos (Davidson \& Chevalier, 1990). Estes, visíveis a partir da expansão da quarta folha do colmo principal, continuam a ser emitidos até o momento em que a planta possui seis a sete folhas completamente expandidas (Masle, 1985).

O presente trabalho foi conduzido para avaliar o efeito do tamanho da semente de trigo sobre o desenvolvimento inicial das plantas e no rendimento dos grãos.

\section{Material e Métodos}

Foram realizados experimentos em condições controladas de ambiente (câmara de crescimento) e no campo.
O experimento em câmara de crescimento foi conduzido na Faculdade de Agronomia da Universidade Federal do Rio Grande do Sul (UFRGS), em Porto Alegre, RS, por um período de 53 dias, até que as plantas apresentassem de oito a nove folhas no colmo principal. As condições estabelecidas para a realização do experimento foram: umidade relativa do ar, $70 \%$; temperatura, $20^{\circ} \mathrm{C}$ diurna e $10^{\circ} \mathrm{C}$ noturna; e radiação luminosa de 12 horas de luz por dia (aproximadamente $0,200 \mathrm{cal} / \mathrm{cm}^{2} / \mathrm{min}$ ) obtida por meio de 12 lâmpadas fluorescentes e 4 incandescentes.

As sementes de trigo da cultivar BR 23 foram classificadas, por peneiras, em cinco diferentes diâmetros: a) menor que $3,0 \mathrm{~mm}$; b) de 3,0 a $3,25 \mathrm{~mm}$; c) de $3,25 \mathrm{a}$ $3,5 \mathrm{~mm}$; d) de 3,5 a $3,75 \mathrm{~mm}$; e) maior que $3,75 \mathrm{~mm}$. As sementes de cada classe foram pré-germinadas em papel germinador durante 96 horas, à temperatura de $25^{\circ} \mathrm{C}$. Após esse período, foram escolhidas 12 plântulas uniformes de cada classe, para serem transplantadas para vasos com solução nutritiva. As plântulas cujo coleóptilo era de cerca de $1 \mathrm{~cm}$ de comprimento foram fixadas na altura do colo, em furos de $2 \mathrm{~cm}$ de diâmetro feitos em placas de isopor, e as raízes, mergulhadas em solução nutritiva. As plantas foram arranjadas simetricamente em cada placa de isopor, ficando distanciadas cerca de $3 \mathrm{~cm}$ entre si. Cada vaso recebeu $5 \mathrm{~L}$ de água destilada e $50 \mathrm{~mL}$ da solução nutritiva de Hoagland modificada, que tem a seguinte composição (expressa em g/L): $\mathrm{KCl}, 14,91 ; \mathrm{MgSO}_{4} \cdot 7 \mathrm{H}_{2} \mathrm{O}$, 24,$33 ; \mathrm{NH}_{4} \mathrm{H}_{2} \mathrm{PO}_{4}, 5,57 ; \mathrm{NH}_{4} \mathrm{NO}_{3}, 8,01 ; \mathrm{Ca}\left(\mathrm{NO}_{3}\right)_{2} .4 \mathrm{H}_{2} \mathrm{O}$, 23,6; Na-EDTA, 3,72; $\mathrm{FeSO}_{4} \cdot 7 \mathrm{H}_{2} \mathrm{O}, 2,78 ; \mathrm{MnSO}_{4} \cdot \mathrm{H}_{2} \mathrm{O}$, 0,076; $\mathrm{CuSO}_{4} .5 \mathrm{H}_{2} \mathrm{O}, 0,118 ; \mathrm{ZnSO}_{4} .7 \mathrm{H}_{2} \mathrm{O}, 0,044 ; \mathrm{H}_{3} \mathrm{BO}_{3}$, 0,143. A renovação da solução foi feita em cada sete dias, pela troca por outra de idêntica composição, sendo aerada continuamente com ar comprimido, num fluxo de $1 \mathrm{~L}$ por minuto. $\mathrm{O}$ pH do meio foi mantido entre 5,0 e 5,5, através da adição de $\mathrm{H}_{2} \mathrm{SO}_{4} 1 \mathrm{~N}$.

Os parâmetros avaliados foram a freqüência de emissão do primeiro afilho (associado à primeira folha do colmo principal), o número de afilhos emitidos (avaliado 43 dias após o transplante, por ocasião da emissão da sexta folha do colmo principal), o comprimento máximo das cinco primeiras folhas, a massa seca das folhas e afilhos (avaliada por ocasião da emissão da sexta folha), e a evolução do estádio de desenvolvimento do colmo principal, utilizando-se a escala proposta por Haun (1973). O valor dado por essa escala reflete o número de folhas completamente expandidas da planta, mais as unidades decimais da última folha (em expansão) relativas à anterior. Por exemplo, uma planta na escala Haun 4.3 tem a quarta folha completamente expandida, e a quinta folha possui três décimos do comprimento da quarta. Nas sementes utilizadas no experimento, foram determinados, em cada classe 
de diâmetro, a massa seca da semente (média de 100 grãos), o teor de N, conforme a metodologia descrita por Tedesco et al. (1995), e a quantidade de N por semente (multiplicando-se a massa seca da semente pelo seu teor de N).

O experimento no campo foi conduzido na Estação Experimental Agronômica (EEA) da UFRGS, localizada no Município de Eldorado do Sul, RS, na região fisiográfica da Depressão Central, a aproximadamente $40 \mathrm{~m}$ de altitude. A precipitação pluvial média anual é de $1.440 \mathrm{~mm}$ e a temperatura média mensal varia de 13,9 a $24,9^{\circ} \mathrm{C}$, entre os meses mais frio e mais quente. $\mathrm{O}$ solo da área experimental pertence à unidade de mapeamento São Jerônimo, classificado como Podzólico Vermelho-Escuro (Paleudult). A análise química do solo antes da instalação do experimento foi determinada em amostra retirada na profundidade de 0-20 $\mathrm{cm}$. Esta análise indicou: $23 \mathrm{~g} / \mathrm{kg}$ de matéria orgânica; $\mathrm{pH}$ em água de 5,7; $8 \mathrm{mg} / \mathrm{kg}$ de $\mathrm{P}$ e $175 \mathrm{mg} / \mathrm{kg}$ de potássio.

As sementes de trigo da cultivar BR 23 foram obtidas do mesmo lote utilizado no experimento em câmara de crescimento, e classificadas, por peneiras, em três diferentes diâmetros: a) menor que $3,0 \mathrm{~mm}$; b) entre 3,0 e $3,5 \mathrm{~mm}$; c) maior que $3,5 \mathrm{~mm}$.

A área experimental estava sob o sistema de plantio direto há quatro anos. A seqüência de culturas foi: milho, no verão; e aveia-preta, no inverno. A adubação prévia da área consistiu da aplicação de 75 e $45 \mathrm{~kg} /$ ha de $\mathrm{P}_{2} \mathrm{O}_{5}$ e $\mathrm{K}_{2} \mathrm{O}$, respectivamente. $\mathrm{ON}$ foi aplicado na dose de $60 \mathrm{~kg} / \mathrm{ha}$, sendo parcelado em $20 \mathrm{~kg} / \mathrm{ha}$ na semeadura e $40 \mathrm{~kg} /$ ha por ocasião da emissão da quinta folha do colmo principal. A semeadura foi realizada no final de junho, na densidade de 300 sementes aptas $/ \mathrm{m}^{2}$. O delineamento experimental utilizado foi o de blocos ao acaso, com quatro repetições, e cada parcela foi constituída de 10 linhas de $5 \mathrm{~m}$ de comprimento, com 0,17 m entre as linhas. Os tratos fitossanitários consistiram no tratamento das sementes com o fungicida Triadimenol ( $1 \mathrm{~g} / \mathrm{kg}$ de i.a.) e na aplicação do fungicida Tebuconazole $(0,75 \mathrm{~L} /$ ha de Folicur), quando do aparecimento das primeiras pústulas de ferrugem-da-folha.

$\mathrm{Na}$ colheita das plantas, foram determinados: a) o rendimento de grãos, em $2,4 \mathrm{~m}^{2}$; b) o número de espigas por área em $2,4 \mathrm{~m}^{2}$; c) a massa média do grão (massa média de 100 grãos); d) o número de grãos por área (dividindo-se o rendimento de grãos pela massa do grão); e) o número de grãos por espiga (dividindo-se o número de grãos por área pelo número de espigas por área).

Os diferentes parâmetros foram submetidos a análise de variância pelo teste $\mathrm{F}$ ou teste do qui-quadrado $\left(\chi^{2}\right)$. A comparação entre médias, quando houve significância para as diferenças entre tratamentos, foi efetuada através do teste de Tukey, a 5\% de probabilidade.

\section{Resultados e Discussão}

A massa seca da semente é considerada uma boa estimativa da quantidade de reservas disponíveis às plantas, de acordo com Bouaziz \& Hicks (1990). Nas sementes utilizadas, ela variou de $26,8 \mathrm{mg}$ (diâmetro menor que $3,0 \mathrm{~mm}$ ) a $52,3 \mathrm{mg}$ por semente (diâmetro maior que $3,75 \mathrm{~mm}$ ) (Tabela 1), valores próximos aos das sementes utilizadas por Grieve \& Francois (1992) (23,2 mg e 49,1 mg por semente). A quantidade de $\mathrm{N}$ por semente também aumentou com a massa da semente, só que em proporção maior do que a massa seca, pois também o teor de $\mathrm{N}$ da semente incrementou à medida que o tamanho da semente aumentou (Tabela 1).

Essas características, associadas ao tamanho da semente, afetaram a emissão de folhas no colmo principal em câmara de crescimento (Figura 1). Isso foi medido pela escala Haun (número de folhas emitidas) nos primeiros 53 dias após o transplantio para a solução nutritiva. Os maiores valores da escala Haun foram observados nas plantas originadas de sementes com diâmetro maior que $3,75 \mathrm{~mm}$, em comparação com as plantas originadas de sementes com diâmetro menor que 3,0 $\mathrm{mm}$. O efeito do tamanho da semente sobre a emissão de folhas no colmo principal persistiu durante todo o período avaliado (Figura 1), conforme também observado por Peterson et al. (1989). Esse comportamento ocorreu devido à maior taxa de emissão de folhas em plantas originadas de sementes maiores durante a expansão das duas primeiras folhas, quando as plântulas estão utilizando as reservas da semente (Peterson et al., 1989).

O tamanho da semente influenciou positivamente o acúmulo de massa seca, mais pronunciado nas três primeiras folhas emitidas, e o comprimento da folha, somente na primeira e segunda folha (Figura 2). Esses efeitos sobre as primeiras folhas provavelmente estão relacionados ao maior tamanho e maior massa seca do embrião em sementes grandes (LópezCastañeda et al., 1996) e à maior quantidade de carboidratos e N nessas sementes (Tabela 1). É importante ressaltar que os primórdios das duas ou três primeiras folhas da planta já estão formados no embrião (Hay \& Kirby, 1991), e que as originadas de sementes grandes podem apresentar maior comprimento e espessura, e, em conseqüência, maior massa 
Tabela 1. Massa seca, teor e quantidade de $\mathrm{N}$ em sementes, freqüência de emissão do primeiro afilho e número médio de afilhos/planta aos 43 dias após o transplante, em plantas de trigo originadas de sementes de diferentes diâmetros, em câmara de crescimento. UFRGS, Porto Alegre, $\mathrm{RS}^{(1)}$.

\begin{tabular}{|c|c|c|c|c|c|}
\hline $\begin{array}{c}\text { Diâmetro da } \\
\text { semente }(\mathrm{mm})\end{array}$ & $\begin{array}{c}\text { Massa seca } \\
(\mathrm{mg} / \mathrm{semente})\end{array}$ & $\begin{array}{c}\text { Teor de N } \\
(\mathrm{g} / \mathrm{kg})\end{array}$ & $\begin{array}{c}\text { Quantidade de } \mathrm{N} \\
(\mathrm{mg} / \text { semente })\end{array}$ & $\begin{array}{c}\text { Freqüência de emissão } \\
\text { do } 1^{\circ} \text { afilho }(\%)\end{array}$ & Afilhos/planta \\
\hline$<3,0$ & $26,8 \mathrm{~d}$ & $23,7 \mathrm{c}$ & $0,63 \mathrm{~d}$ & $25^{(2)}$ & $4,1 b$ \\
\hline $3,0-3,25$ & $40,7 \mathrm{c}$ & $23,6 \mathrm{c}$ & $0,96 \mathrm{c}$ & 42 & $5,1 \mathrm{ab}$ \\
\hline $3,25-3,5$ & $42,1 \mathrm{c}$ & $24,0 \mathrm{c}$ & $1,01 \mathrm{c}$ & 50 & $5,4 \mathrm{ab}$ \\
\hline $3,5-3,75$ & $48,2 b$ & $25,6 b$ & $1,23 b$ & 67 & $5,6 \mathrm{ab}$ \\
\hline$>3,75$ & $52,3 \mathrm{a}$ & $28,0 \mathrm{a}$ & $1,46 a$ & 75 & $7,0 \mathrm{a}$ \\
\hline
\end{tabular}

(1)Médias seguidas pela mesma letra na coluna não diferem estatisticamente entre si, pelo teste de Tukey, a 5\% de probabilidade. (2)Diferenças entre tratamentos em relação à freqüência de emissão do primeiro afilho são significativas pelo teste do $\chi^{2}$, a $10 \%$ de probabilidade.

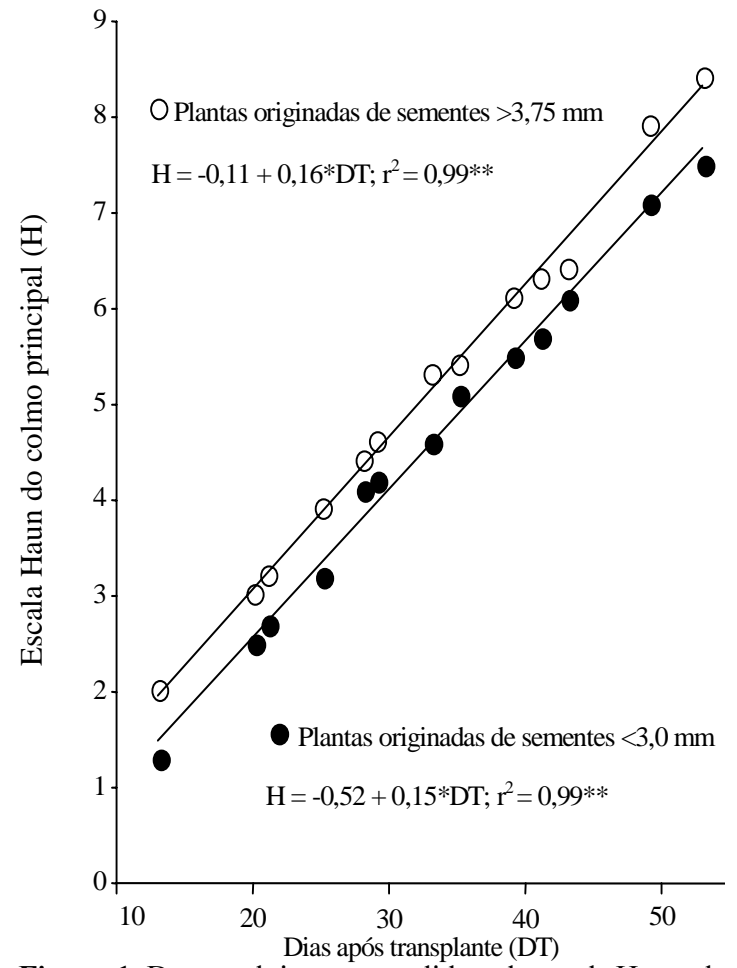

Figura 1. Desenvolvimento, medido pela escala Haun, do colmo principal de plantas de trigo originadas de sementes de diferentes diâmetros, em câmara de crescimento. UFRGS, Porto Alegre, RS.

seca. López-Castañeda et al. (1996) argumentaram que as plantas originadas de sementes com embriões maiores possuem maior vigor, porque quando se inicia a embebição da semente, mais células estão se expandindo e as zonas meristemáticas são maiores.

$\mathrm{O}$ fato de na primeira folha ter-se observado pequeno efeito do tamanho da semente (Figura 2) pode ser decorrente de que, durante a expansão dessa folha, a demanda de nutrientes pela parte aérea é mínima, e mesmo sementes de pequeno diâmetro possuem quantidades suficientes de reservas para suprir a expansão da primeira folha. Quando se iniciou a expansão da segunda folha, cerca de dez dias após o transplante, as reservas do endosperma nas sementes pequenas já estavam praticamente esgotadas, enquanto as sementes grandes ainda foram capazes de suprir a planta com nutrientes do endosperma até que a segunda folha estivesse expandida, como também relatado por Peterson et al. (1989). O comprimento das folhas subseqüentes foi similar entre os tratamentos (Figura 2), pois, uma vez esgotadas as reservas da semente, as plantas passaram a absorver os nutrientes da solução nutritiva, a qual foi idêntica entre os tratamentos.

Esses efeitos sobre as folhas do colmo principal também foram detectados nas folhas dos afilhos, os quais se refletiram na freqüência de emissão do primeiro afilho, no número de afilhos emitidos por planta, e na massa seca dos afilhos.

Em relação ao primeiro afilho, verificou-se que, à medida que aumentou o tamanho da semente, ocorreu um aumento na freqüência de sua emissão (Tabela 1). A emissão desse afilho é fundamental para a determinação do número de espigas produzidas pela planta, uma vez que os primeiros afilhos emitidos possuem maiores chances de sobreviver e produzir grãos (Hucl \& Baker, 1991). Além disso, a alta disponibilidade de nutrientes desde o início do ciclo, principalmente o $\mathrm{N}$, é fundamental para que não ocorra a omissão de afilhos primários, especialmente do primeiro afilho, conforme observado por Longnecker et al. (1993). Em trigo, a definição da emissão, ou não, de afilhos, ocorre muito precocemente no ciclo da planta (entre os estádios de uma a duas folhas ex- 

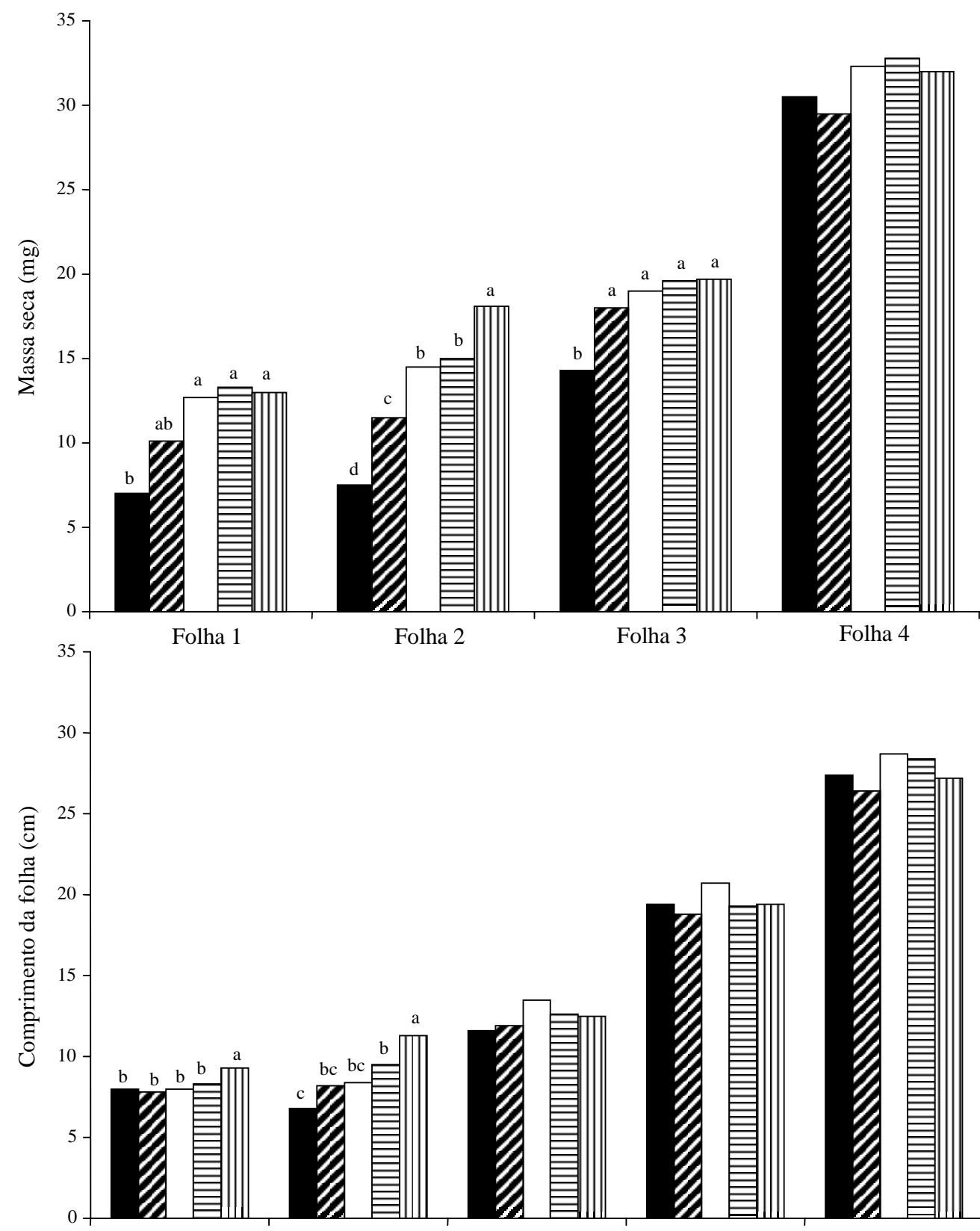

Folha 2

Folha 3

Folha 4

Folha 1

\section{Folha 2}

Folha 3

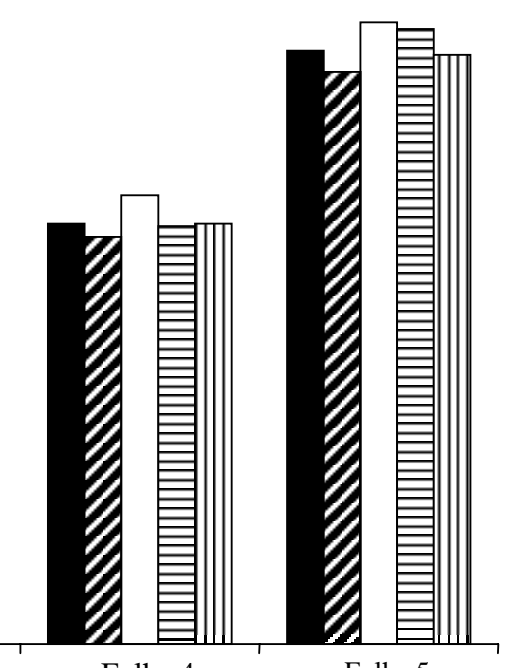

Folha 4

Folha 5

Folhas do colmo principal

口 $<3,0 \mathrm{~mm} \quad \square 3,0-3,25 \mathrm{~mm} \quad \square 3,25-3,5 \mathrm{~mm} \quad \square 3,5-3,75 \mathrm{~mm}$

$>3,75 \mathrm{~mm}$

Figura 2. Massa seca e comprimento máximo de folhas de plantas de trigo originadas de sementes de diferentes diâmetros, em câmara de crescimento. Médias com mesma letra não diferem entre si, pelo teste de Tukey, a 5\% de probabilidade. UFRGS, Porto Alegre, RS. 
pandidas), conforme mostrado por Almeida (1998), e esta pode ser afetada pela disponibilidade de nutrientes. As sementes grandes disponibilizaram maior quantidade de $\mathrm{N}$ às plantas nos estádios iniciais de desenvolvimento, aumentando, assim, a freqüência de emissão do primeiro afilho e o número de afilhos emitidos (Tabela 1), conforme também observado por Grieve \& François (1992).

Além do aumento no número de afilhos, as plantas originadas de sementes maiores produziram afilhos com maior massa seca (Figura 3). Esta foi medida 53 dias após o transplante, observando-se que o efeito foi mais acentuado nos afilhos emitidos mais cedo (primeiro e segundo afilhos). Esta resposta pode ser relacionada à anatomia vascular das plântulas, pois as conexões vasculares entre o colmo principal e os primeiros afilhos são pouco desenvolvidas em sementes com poucas reservas, prejudicando, assim, o crescimento dos afilhos (Peterson et al., 1982).

As relações entre o tamanho da semente e o crescimento e desenvolvimento das plantas testadas no campo não se refletiram em aumento no rendimento de grãos (Tabela 2). Provavelmente, esta resposta não está somente relacionada à produção, mas também à

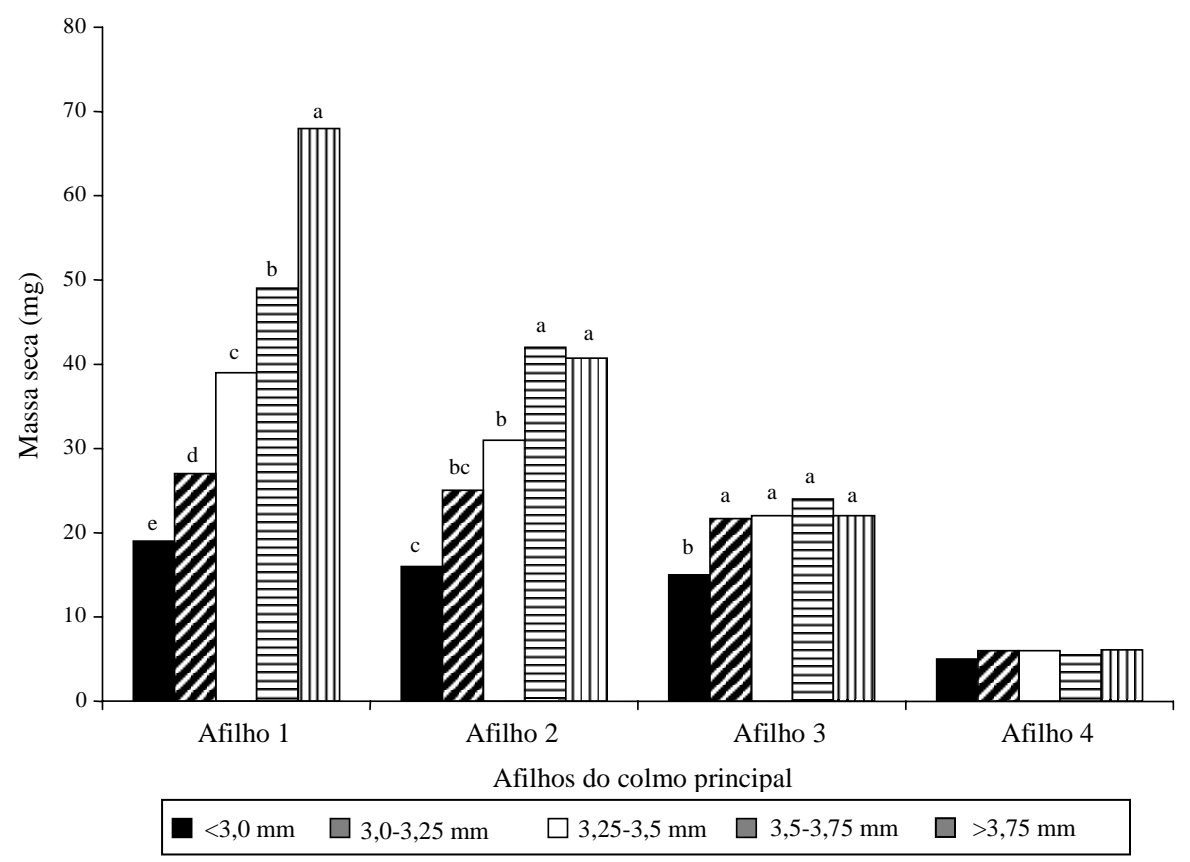

Figura 3. Massa seca de afilhos de plantas de trigo originadas de sementes de diferentes diâmetros, em câmara de crescimento. Médias com a mesma letra não diferem entre si, pelo teste de Tukey, a 5\% de probabilidade. UFRGS, Porto Alegre, RS.

Tabela 2. Rendimento de grãos e seus componentes afetados pelo diâmetro da semente de trigo no campo. UFRGS, Eldorado do Sul, $\mathrm{RS}^{(1)}$.

\begin{tabular}{cccccc}
\hline $\begin{array}{c}\text { Diâmetro da } \\
\text { semente }(\mathrm{mm})\end{array}$ & $\begin{array}{c}\text { Rendimento de } \\
\text { grãos }(\mathrm{kg} / \mathrm{ha})\end{array}$ & Espigas $/ \mathrm{m}^{2}$ & Grãos/espiga & Grãos $/ \mathrm{m}^{2}$ & Massa do grão (mg) \\
\hline$<3,0$ & 2.308 & 288 & 20,1 & 6.041 & 38,2 \\
$3,0-3,5$ & 2.197 & 314 & 20,0 & 5.812 & 37,8 \\
$>3,5$ & 2.505 & 300 & 22,3 & 6.715 & 37,3 \\
\hline
\end{tabular}

(1) Os valores de F não foram significativos. 
sobrevivência de afilhos e seus efeitos sobre os componentes do rendimento de grãos.

Na câmara de crescimento, a maior quantidade de reservas na semente foi efetiva em aumentar o número de afilhos emitidos e a freqüência de emissão do primeiro afilho. Este efeito, porém, parece não ter sido importante para a cultivar BR 23, nas condições existentes no experimento em campo.

A cultivar BR 23 praticamente independe do componente número de espigas $/ \mathrm{m}^{2}$ para fixar o rendimento de grãos em condições normais de cultivo (Mundstock \& Bredemeier, 1994). O principal componente que afeta o rendimento de grãos é o número de grãos por espiga e este não foi alterado pelo tamanho da semente, e foi baixo em todos os tratamentos (Tabela 2). Uma vez que a quantidade de afilhos emitidos e sobreviventes poderia afetar o número de espigas produzidas, verificou-se que os afilhos foram pouco importantes para determinar o número de espigas e o rendimento de grãos na cultivar BR 23. Este efeito está relacionado ao grande número de mortes de afilhos que ocorrem a partir do estádio de sete folhas expandidas (Longnecker et al., 1993), e este fenômeno pode ter ocorrido, pois o número de espigas produzidas (Tabela 2) não variou com o tamanho da semente, e atingiu valores que normalmente são obtidos nestas condições de cultivo (Mundstock \& Bredemeier, 1994).

Os afilhos foram pouco importantes na determinação do rendimento de grãos, seja pelos baixos tetos de rendimento, seja por características próprias da cultivar, como no caso da cultivar BR 23, cuja vantagem inicial da maior quantidade de reservas sobre o afilhamento não se mantém até o final do ciclo. No campo, outros fatores tornam-se mais limitantes para o desenvolvimento das plantas, como a disponibilidade de $\mathrm{N}$ e a competição intra e interespecífica (Bremner et al., 1963).

Os efeitos do tamanho da semente tampouco foram detectados sobre o terceiro componente do rendimento, a massa do grão. Os valores encontrados não sofreram alteração (Tabela 2), e situaram-se muito próximo dos normalmente obtidos nesta cultivar (Mundstock \& Bredemeier, 1994).

\section{Conclusões}

1. O desenvolvimento inicial do trigo, medido pela taxa de emissão de folhas do colmo principal é maior em plantas oriundas de sementes de maior tamanho.
2. O crescimento das plantas, medido pela massa seca e pelo comprimento da folha, é mais acentuado nas primeiras folhas e afilhos, e menos intenso nos afilhos mais tardios.

3. O maior desenvolvimento inicial das plantas originadas de sementes grandes não se expressa necessariamente em aumento no rendimento de grãos.

4. A maior quantidade de reservas na semente é pouco importante em cultivares que apresentam baixa sobrevivência de afilhos e independem dos afilhos para determinar o número de espigas produzidas.

\section{Referências}

ALMEIDA, M. L. Modificação do afilhamento de trigo e aveia pela qualidade da luz. Porto Alegre : UFRGS, 1998. 121 p. Tese de Doutorado.

BOUAZIZ, A.; HICKS, D. R. Consumption of wheat seed reserves during germination and early growth as affected by soil water potential. Plant and Soil, Dordrecht, v. 128, p. $161-165,1990$.

BREMNER, P. M.; ECKERSALL, R. N.; SCOTT, R. K. The relative importance of embryo size and endosperm size in causing the effects associated with seed size in wheat. Journal of Agricultural Science, Cambridge (Inglaterra), v. 61, p. 139-145, 1963.

DAVIDSON, D. J.; CHEVALIER, P. M. Preanthesis tiller mortality in spring wheat. Crop Science, Madison, v. 30, p. 832-836, 1990.

GRIEVE, C. M.; FRANCOIS, L. E. The importance of initial seed size in wheat response to salinity. Plant and Soil, Dordrecht, v. 147, p. 197-205, 1992.

HAUN, J. R. Visual quantification of wheat development. Agronomy Journal, Madison, v. 65, p. 116-119, 1973.

HAY, R. K. M.; KIRBY, E. J. M. Convergence and synchrony: a review of the coordination of development in wheat. Australian Journal of Agricultural Research, Collingwood, v. 42, p. 661-700, 1991.

HUCL, P.; BAKER, R. J. Performance of oligoculm spring wheats grown in a semiarid environment. Canadian Journal of Plant Science, Ottawa, v. 71, p. 199-203, 1991.

LAFOND, G. P.; BAKER, R. J. Effects of genotype and seed size on speed of emergence and seedling vigor in nine spring wheat cultivars. Crop Science, Madison, v. 26, p. 341-346, 1986. 
LONGNECKER, N.; KIRBY, E. J. M.; ROBSON, A. Leaf emergence, tiller growth, and apical development of nitrogen-deficient spring wheat. Crop Science, Madison, v. 33 , p. $154-160,1993$

LÓPEZ-CASTAÑEDA， C.; RICHARDS, R. A.; FARQUHAR, G. D.; WILLIAMSON, R. E. Seed and seedling characteristics contributing to variation in early vigor among temperate cereals. Crop Science, Madison, v. 36, p. 1257-1266, 1996.

LOWE, L. B.; RIES, S. K. Endosperm protein of wheat seed as a determinant of seedling growth. Plant Physiology, Rockville, v. 51, p. 57-60, 1973.

MASLE, J. Competition among tillers in winter wheat: consequences for growth and development of the crop. In: DAY, W.; ATKIN, R. K. (Ed.). Wheat growth and modeling. New York: Plenum, 1985. p. 33-54.

MIAN, M. A. R.; NAFZIGER, E. D. Seed size and water potential effects on germination and seedling growth of winter wheat. Crop Science, Madison, v. 34, p. 169-171, 1994.

MUNDSTOCK, C. M.; BREDEMEIER, C. Época de aplicação de nitrogênio em trigo: resposta dos componentes do rendimento. In: REUNIÂO NACIONAL DE PESQUISA DE TRIGO, 17., 1994, Passo Fundo. Anais... Passo Fundo : Embrapa-CNPT, 1994. p. 215-216.

PETERSON, C. M.; KLEPPER, B.; RICKMAN, R. W. Seed reserves and seedling development in winter wheat. Agronomy Journal, Madison, v. 81, p. 245-251, 1989.

PETERSON, C. M.; KLEPPER, B.; RICKMAN, R. W. Tiller development at the coleoptilar node in winter wheat. Agronomy Journal, Madison, v. 74, p. 781-784, 1982.

POPINIGIS, F. Fisiologia da semente. Brasília : AGIPLAN, 1977. 289 p.

TEDESCO, M. J.; GIANELLO, C.; BISSANI, C. A. Análises de solo, plantas e outros materiais. 2. ed. Porto Alegre: UFRGS, 1995. 174 p. (Boletim Técnico de Solos, 5). 